\title{
PESQUISA EM EDUCAÇÃO E A ABORDAGEM DO CICLO DE POLÍTICAS: UMA EXPERIÊNCIA DE PESQUISA
}

\author{
EDUCATIONAL RESEARCH AND THE POLICY CYCLE APPROACH: A RESEARCH \\ EXPERIENCE
}

\begin{abstract}
INVESTIGACIÓN EDUCATIVA Y ENFOQUE DEL CICLO DE POLÍTICAS: UNA EXPERIENCIA DE INVESTIGACIÓN
\end{abstract}

\author{
Ana de Fátima P. de Sousa Abranches \\ Fundação Joaquim Nabuco - Brasil \\ Danielle Silva da Rocha Correia \\ Secretaria de Educação de Olinda - Brasil
}

\begin{abstract}
Resumo: O presente artigo busca contribuir com a área de política educacional discutindo e analisando a experiência de uma orientação em nível de mestrado que utilizou a Abordagem do Ciclo de Políticas como referencial analítico proposto pelo sociólogo inglês Stephen J. Ball e colaboradores (BOWE; BALL; GOLD, 1992; BALL; BOWE, 1992; BALL, 1994). O estudo trata de tema contemporâneo em destaque no contexto educacional e político, no caso a constituição do setor de Política das Relações Étnico-Raciais em uma rede de ensino municipal e, deste modo a abordagem do Ciclo de Políticas foi essencial como abordagem teórica e analítica da pesquisa. Os estudos realizados por Ball e Bowe (1992), Ball (2004), Ball e Mainardes (2011) e Lopes (2004) foram basilares para a condução da pesquisa aqui analisada. Por fim, é oportuno reafirmar que o uso da abordagem do Ciclo de Políticas permitiu ampliar a compreensão do fenômeno em análise - a execução da política de relações étnico-raciais - não a limitando a uma simples verificação de aplicação de determinada teoria, mas, ao contrário, desvelando os caminhos, por vezes contraditórios, de sua construção.
\end{abstract}

Palavras-chave: Ciclo de Políticas. Política Educacional. Relações Étnico-Raciais.

\begin{abstract}
The present article aims to contribute to the area of education policy by discussing and analyzing the experience of a master's level orientation that used the Policy Cycle Approach as an analytical framework proposed by the English sociologist Stephen J. Ball and collaborators (BOWE; BALL; GOLD, 1992; BALL; BOWE, 1992; BALL, 1994). The study deals with the contemporary theme highlighted in the educational and political context, in this case the constitution of the EthnicRacial Relations Policy sector in a municipal education department and, thus, the Policy Cycle approach was essential as a theoretical and analytical approach of the research. The studies carried out by Ball and Bowe (1992), Ball (2004), Ball and Mainardes (2011) and Lopes (2004) were fundamental for conducting the research analyzed here. Finally, it is important to reaffirm that the use of the Policy Cycle approach allowed to widen the understanding of the phenomenon under analysis - the implementation of the policy of ethnic-racial relations - not limiting it to a simple verification of the application of a certain theory, but on the contrary, unveiling the paths, sometimes contradictory, of its construction.
\end{abstract}

Keywords: Education Policy. Ethnic-Racial Relations. Policy Cycle. 
Resumen: El presente artigo busca contribuir hacia el campo de política educacional discutiendo y analizando la experiencia de una orientación a nivel de maestría que utilizó el Abordaje del Ciclo de Políticas como referencial analítico propuesto por el sociólogo inglés Stephen J. Ball y colaboradores (BOWE; BALL; GOLD, 1992; BALL; BOWE, 1992; BALL, 1994). El estudio trata del tema contemporáneo en relieve en el contexto educacional y político, esto es, la constitución del sector de Políticas de las Relaciones Étnico-Raciales en una red de enseñanza municipal y, de este modo el abordaje del Ciclo de Políticas fue esencial como abordaje teórica y analítica de la investigación. Los estudios realizados por Ball y Bofe (1992), Ball (2004), Ball e Mainardes (2011) e Lopes (2004) fueron fundamentales para la conducción de la investigación aquí analizada. Por fin, es oportuno reafirmar que el uso del abordaje del Ciclo de Políticas permitió ampliar la comprensión del fenómeno en análisis - la ejecución de la política de las relaciones étnico-raciales - sin limitarla apenas a una sencilla verificación de la aplicación de una determinada teoría, sin embargo, al revés, desvelando los caminos, por veces contradictorios, de su construcción.

Palabras clave: Ciclo de Políticas. Política Educacional. Relaciones Étnico-Raciales.

\section{Introdução}

A pesquisa em Educação é um campo amplo e aberto, já consolidado, possuindo diversos grupos específicos e áreas temáticas. Dentre essas, é possível destacar o campo de políticas educacionais em expansão e contínua construção.

Neste artigo, tomamos como foco a área de políticas educacionais, sendo esta uma das áreas que vem se fortalecendo no campo das pesquisas em educação com trabalhos científicos e estudos consolidados, pontuando a riqueza teórica e metodológica que lhe é pertinente, que abrange desde ações específicas e projetos de intervenção na prática pedagógica até estudos sobre concepções e princípios de política governamental na área educacional.

Dentro deste universo de estudos e pesquisa sobre políticas educacionais, discutiremos neste texto a pesquisa e o uso de referencial teórico e analítico específico que fundamenta a metodologia utilizada. Em outras palavras, nos interessa analisar como pesquisas em políticas educacionais usam aportes teóricos que estruturam e organizam o quadro metodológico tendo como base os contextos da Abordagem do Ciclo de Políticas como referencial analítico proposto pelo sociólogo inglês Stephen J. Ball e colaboradores (BOWE; BALL; GOLD, 1992; BALL; BOWE, 1992; BALL, 1994).

Neste sentido, o artigo se propõe a descrever e analisar a experiência de orientação acadêmica de uma dissertação composta por estudo bibliográfico, análise documental e entrevista, sendo estruturada na perspectiva analítica da abordagem do Ciclo de Políticas. 
Assim, orientadora e orientanda escrevem o presente texto ${ }^{1}$ no sentido da partilha da experiência acadêmica de orientação e coadunando com o educador Paulo Freire (1996) quando afirma "Não há docência sem discência". O diálogo profícuo objetivou promover uma maior compreensão da área de Política Educacional na medida que o estudo buscou humanizar o seu contexto, no sentido de compreender quem faz a política educacional, que grupos e instituições influenciaram sobremaneira políticas formuladas que são efetivadas.

Assim, podem existir espaços dentro de espaços. Podemos refletir a respeito das políticas em termos de espaços e em termos de tempo, de trajetórias políticas, movimentos de políticas através do tempo e de uma variedade de espaços. (BALL apud MAINARDES; MARCONDES, 2009, p. 307).

A pesquisa, foco do presente artigo, analisa o objeto de estudo a partir dos Contexto da Influência, Contexto da Produção de Texto e Contextos da Prática. O estudo trata de tema contemporâneo em destaque no contexto educacional e político e, deste modo, a abordagem do Ciclo de Políticas foi essencial como abordagem teórica e analítica da pesquisa. Os estudos realizados por Ball e Bowe (1992), Ball (2004), Ball e Mainardes (2011) e Lopes (2004) foram basilares para a condução da pesquisa aqui analisada.

Deste modo, este texto se organiza em seções distintas, apresentando na próxima seção a discussão sobre a pesquisa em Educação, com ênfase nas políticas educacionais, de modo a delimitar claramente o escopo desta discussão. A seguir, apresentamos e discutimos a abordagem do Ciclo de Políticas de Stephen Ball (1994) que é foco deste estudo no âmbito da política educacional, destacando os aspectos que são utilizados na pesquisa selecionada. Logo após, apresentamos a orientação, e o percurso metodológico da pesquisa selecionada para este estudo, sendo ela fruto de orientação acadêmica em âmbito de mestrado, para, na seção seguinte, situarmos o Ciclo de Políticas na análise de políticas educacionais voltadas à temática étnico-racial e para criação do Grupo de Trabalho para Educação da Relações Étnicos-Raciais (GTERE). Em continuidade, fazemos a apresentação dos contextos políticos e sociais dos períodos de desenvolvimentos das políticas local e a seção final se ocupa de discutir os dados e refletir sobre os sentidos que tais usos trazem para as pesquisas em política educacional.

\section{A pesquisa em Educação e especificamente das políticas educacionais}

A pesquisa em Educação, como já afirmado aqui, é um campo já consolidado e em expansão, sendo reconhecida no conjunto das pesquisas na grande área de Humanas. Este

\footnotetext{
${ }^{1}$ Este artigo contém citações indiretas da dissertação analisada, estando esta publicada no site do Programa de Pós-graduação.
} 
aspecto demonstra a consolidação de diversos esforços no sentido da delimitação e mesmo da identidade dos estudos que tratam do fenômeno educacional em suas diversas facetas. $\mathrm{O}$ advento da Pós-graduação no Brasil é marco fundamental neste processo de constituição e consolidação das pesquisas no campo da educação, uma vez que foram criados canais institucionais para o seu desenvolvimento, o que se espalhou por todas as regiões do país. Atualmente são mais de 190 programas de pós-graduação em educação (CAPES, 2016), com cursos de mestrado e doutorado, espalhados em todas as regiões do país.

O histórico da pós-graduação em educação no Brasil aponta as mudanças que este campo sofreu ao longo dos anos, incorporando temáticas específicas e delimitando objetos de estudo. É neste sentido que o campo das políticas educacionais se consolidou, aprofundando como seu foco o estudo de programas, projetos e demais ações dos diferentes agentes educacionais na configuração de propostas e práticas para a ação educacional, em especial dos sistemas educacionais, bem como a percepção desses mesmos agentes na consecução de tais práticas.

Falar em política educacional nos leva diretamente a uma ação minimamente estruturada, com objetivo de intervenção na realidade educacional, buscando atingir fins determinados. É assim que as pesquisas neste campo se debruçam no intuito de analisar tal realidade, seus impactos e as percepções dos sujeitos envolvidos, sejam eles autores desta política educacional ou os seus favorecidos.

Como fenômeno social, as políticas educacionais têm sua dinâmica própria, mesmo que fortemente influenciadas pelo contexto em que se inserem e sobre ele produzem seus impactos. Por isso, entender este processo característico das políticas educacionais permite um maior aprofundamento e compreensão do significado que elas carregam para os sujeitos envolvidos e a sociedade em geral.

Para Azevedo (1997), as políticas públicas são normas, símbolos, valores e representações sociais desenvolvidas pelas sociedades sobre elas mesmas, que constroem e integram o universo simbólico e cultural de determinadas realidades. Essas políticas, efetivadas, reelaboradas ou desativadas, baseiam-se na memória do Estado ou da sociedade em que têm lugar, e guardam, desta forma, relações estreitas com as representações sociais acima citadas. A autora chama a atenção para os recursos de poder que operam na definição dessas políticas, que têm nas instituições do Estado, sobretudo na máquina governamental, a sua referência principal.

A abordagem do Ciclo de Políticas, proposta por Stephen Ball e colaboradores (BOWE; BALL; GOLD, 1992; BALL, 1994), se apresenta então como uma forma privilegiada de 
entender a dinâmica própria da política educacional, aspecto a ser aprofundado na seção a seguir.

\title{
A abordagem do Ciclo de Políticas
}

No contexto da política educacional, a abordagem do Ciclo de Políticas desenvolvido pelo sociólogo inglês Stephen Ball e colaboradores (BOWE; BALL; GOLD, 1992; BALL, 1994) vem sendo utilizada em diferentes países como um referencial para analisar a trajetória de políticas sociais e educacionais, contribuindo sobremaneira nas possibilidades de compreender as políticas nos aspectos macro e micro, na medida em que proporciona uma leitura a partir do que denomina de três contextos que não são entendidos como lineares (BALL; BOWE, 1992 apud MAINARDES, 2006).

A partir de um referencial teórico e analítico, eles fundamentam os ciclos da política didaticamente em uma perspectiva que detalha a formação do ciclo e seu movimento complexo de elaboração e execução de um programa ou política (MAINARDES, 2006) e como os formuladores e executores participam da mesma. A abordagem do Ciclo de Políticas é formulada por Stephen Ball e Richard Bowe (MAINARDES, 2006) num primeiro momento em 1992 e no segundo momento já com mais estudos e reflexões com Stephen Ball em 1994 com o seguinte desenho didático:

\begin{abstract}
Os autores propuseram um ciclo contínuo constituído por três contextos principais: o contexto de influência, o contexto da produção de texto e o contexto da prática. Esses contextos estão inter-relacionados, não têm uma dimensão temporal ou sequencial e não são etapas lineares. Cada um desses contextos apresenta arenas, lugares e grupos de interesse e cada um deles envolve disputas e embates (Bowe et al., 1992). Em 1994, no livro Education reform: a critical and post-structural approach, Ball (1994a) expandiu o Ciclo de Políticas acrescentando outros dois contextos ao referencial original: o contexto dos resultados (efeitos) e o contexto da estratégia política. (MAINARDES, 2006, p. 8).
\end{abstract}

Atinentes à importância da temática e do processo metodológico entendemos que a abordagem do Ciclo de Políticas formulado por Ball contribui significativamente na análise de políticas, pois compreende o processo político como dinâmico e multifacetado, articulando assim as perspectivas micro e macro e suas interpenetrações e ao destaque bem colocado sobre o impacto das políticas sobre grupos específicos. Segundo Ball e Mainardes (2011), políticas sobre gênero, raça, classe, entre outros, são extremamente necessárias, afirmação essa que evidencia a preocupação do autor com questões de justiça social, padrões de acesso e oportunidades sociais (MAINARDES, 2006). A abordagem do Ciclo de Políticas oferece 
instrumentos para que realizemos uma análise da trajetória das políticas educacionais, numa abordagem crítica, contextualizada, e ao mesmo tempo, flexível.

\section{A orientação e o percurso metodológico}

No trabalho na pós-graduação Stricto Sensu, selecionamos uma dissertação para este artigo e apresentamos o desenho, a finalidade e as análises dos dados pesquisados, cuja orientação dos estudos tem suporte teórico e metodológico da abordagem do Ciclo de Políticas.

No contexto da pesquisa Stricto Sensu, o estudo e o processo de dissertação foram sendo norteados pela formulação do problema de pesquisa, definição do enfoque teórico, delimitação do objeto e a partir deste movimento de estudo a definição da metodologia e os procedimentos de análises. A construção metodológica da pesquisa em pauta tem como base a perspectiva e o posicionamento epistemológico crítico. "O enfoque epistemológico é o modo como se constrói metodologicamente a pesquisa com base em determinada perspectiva epistemológica e posicionamento epistemológico" (MAINARDES, 2018, p. 6).

A pesquisa foi finalizada em 2020 e tinha como objeto de estudo temática relacionada à área educacional que suscitou análise que buscasse compreender o contexto mais amplo do objeto situando-o no contexto histórico, social e das políticas educacionais no Brasil e no mundo, e neste contexto a escolha da Abordagem do Ciclo de Políticas tem no objeto da pesquisa a referência

Reafirmamos que a pesquisa elencada se posiciona epistemologicamente na Análise Crítica na perspectiva da equidade e inclusão social e estudou a docência frente aos desafios da profissão, e foi intitulada “A política de formação docente para a educação das relações ÉtnicoRaciais na Rede Municipal de Educação do Recife e o Grupo de Trabalho em Educação para as Relações Étnico-Raciais - GTERE (2006-2018)”, de autoria de Danielle Silva da Rocha Correia.

O objeto estudado foi a trajetória e efetivação da política de formação docente para a Educação das Relações Étnico-Raciais e o papel do GTERE (Grupo de Trabalho em Educação para as Relações Étnico-Raciais) na Rede Municipal de Recife, nos períodos de 2006 a 2008, e delineou a trilha metodológica com questões que nortearam o estudo, como:

a) Que influências sofreram as políticas de formação docente para a Educação das Relações Étnico-Raciais na Rede Municipal de Recife?

b) Quais os documentos legais que orientam tais políticas de formação, e quais os contextos de produção dos mesmos? 
c) Como são realizadas, na prática, essas políticas de formação voltadas à temática étnico-racial?

d) Como se deu a atuação do Grupo de Trabalho em Educação para as Relações Étnico-Raciais?

Para obtermos os dados para a análise, optamos como modalidade de pesquisa científica por uma investigação qualitativa a partir do estudo bibliográfico, documental e entrevistas, entendendo que a pesquisa qualitativa se apresenta adequado para firmar os conceitos e objetivos a serem alcançados e dar sugestões sobre variáveis a serem estudadas com maior profundidade acerca da temática em foco. Segundo André (2013, p. 97),

As abordagens qualitativas de pesquisa se fundamentam numa perspectiva que concebe o conhecimento como um processo socialmente construído pelos sujeitos nas suas interações cotidianas, enquanto atuam na realidade, transformando-a e sendo por ela transformados.

Tais estudos exigem clareza e posicionamento teórico e epistemológico, na medida que são pesquisas que buscam analisar propostas que abrangem discussões sobre o papel do Estado e neste caso é fundamental entender as redes de influências que dão suporte aos movimentos de determinada política ou programa, bem como os documentos que foram gerados a partir das respectivas redes de influência e em que medida as ações são compactuadas no movimento maior das produções das políticas ou programas, e como no contexto da prática as políticas são efetivadas, sejam elas no nível macro e micro. Na citação a seguir, em entrevista, Ball apresenta elementos importantes sobre a metodologia:

O principal ponto que gostaria de destacar é o de que o Ciclo de Políticas é um método. Ele não diz respeito à explicação das políticas. É uma maneira de pesquisar e teorizar as políticas. Algumas pessoas o leram e interpretaram como se eu estivesse descrevendo políticas e os processos de elaborá-las. O Ciclo de Políticas não tem a intenção de ser uma descrição das políticas, é uma maneira de pensar as políticas e saber como elas são "feitas", usando alguns conceitos que são diferentes dos tradicionais como, por exemplo, o de atuação ou encenação (enactment).4 Quero rejeitar completamente a ideia e que as políticas são implementadas. Eu não acredito que políticas sejam implementadas, pois isso sugere um processo linear pelo qual elas se movimentam em direção à prática de maneira direta. Este é um uso descuidado e impensado do verbo. O processo de traduzir políticas em práticas é extremamente complexo; é uma alternação entre modalidades. A modalidade primária é textual, pois as políticas são escritas, enquanto que a prática é ação, inclui o fazer coisas. Assim, a pessoa que põe em prática as políticas tem que converter/transformar essas duas modalidades, entre a modalidade da palavra escrita e a da ação, e isto é algo difícil e desafiador de se fazer. E o que isto envolve é um processo de atuação, a efetivação da política na prática e através da prática [...] A prática é composta de muito mais do que a soma de uma gama de políticas e é tipicamente investida de valores locais e pessoais e, como tal, 
envolve a resolução de, ou luta com, expectativas e requisitos contraditórios acordos e ajustes secundários fazem-se necessários. (BALL apud MAINARDES; MARCONDES, 2018, p. 305).

Nesse caminho, nossa análise baseou-se no contexto de influência, no contexto de produção de texto e no contexto da prática. "Esses contextos estão inter-relacionados, não têm uma dimensão temporal ou sequencial e não são etapas lineares. Cada um desses contextos apresenta arenas, lugares e grupos de interesse e cada um deles envolve disputas e embates" (BOWE; BALL; GOLD, 1992 apud MAINARDES, 2006, p. 50).

O contexto de influência corresponde à arena em que "[...] o discurso em formação algumas vezes recebe apoio e, outras vezes, é desafiado por princípios e argumentos mais amplos que estão exercendo influência nas arenas públicas de ação, particularmente" (MAINARDES, 2006, p. 51). Buscamos identificar na pesquisa bibliográfica e documental, bem como nas falas dos entrevistados, qual ou quais contextos políticos influenciaram na construção das políticas de formação para a educação das relações étnico-raciais nos períodos pesquisados.

Articulado ao contexto anterior, o contexto de produção de texto apresenta-se em diversas configurações: textos oficiais, jurídicos, políticos etc., e deve ser compreendido a partir das suas possibilidades e limitações materiais, assim como devem ser considerados o tempo e o local em que tais textos foram produzidos (MAINARDES, 2006). Neste sentido, dedicamonos aos documentos legais que orientam as políticas de formação para a Educação das Relações Étnico-Raciais e aos contextos de produção dos mesmos.

Já o contexto da prática é “[...] onde a política está sujeita à interpretação e recriação e onde a política produz efeitos e consequências que podem representar mudanças e transformações significativas na política original” (MAINARDES, 2006, p. 53). Nossa análise nos permitiu uma melhor compreensão sobre as políticas de formação para a Educação das Relações Étnico-Raciais e a atuação do GTERE no referido contexto.

Ressaltamos, ainda, a existência de outros dois contextos: o contexto dos resultados (efeitos) e o contexto da estratégia política. Contudo, optamos em trabalhar com os três primeiros contextos, por aproximarem-se mais dos nossos objetivos de pesquisa. Buscamos compreender os contextos da influência, da produção de textos e da prática nas perspectivas global, nacional e local que impulsionaram os estudos atinentes à formação de professores(as) na temática das relações étnico-raciais que norteou o tema em pauta. Assim, buscamos identificar como a temática se situa no marco temporal da política global, nacional e local, e nas falas dos entrevistados, e identificar qual ou quais contextos políticos influenciaram na 
construção das políticas de formação para a educação das relações étnico-raciais no período pesquisado na cidade do Recife.

Para fazermos as análises, recorremos aos fundamentos teóricos do estudo e às pesquisas correlacionadas, estabelecendo conexões e relações que nos permitiram apontar as descobertas do nosso estudo. A partir daí, tivemos elementos para uma análise calcada na pluralidade conceitual e aprofundada acerca das políticas de formação continuada dos docentes sobre as relações étnico-raciais.

Entendemos que as políticas de formação para a educação das relações étnico-raciais se constituem um direito social a ser cada vez mais presente nas produções científicas. Garantir seu debate e inclusão nas pesquisas torna-se desafiador, daí a importância de situá-las na perspectiva de transformação estrutural e sócio histórica do campo educacional e científico. O desenvolvimento de pesquisas acerca dos saberes étnico-raciais, seja no campo das políticas, da educação, da história, da cultura, da religião, entre outros aspetos, configura-se como um desafio acadêmico, mas também um desafio político e social, pois por muito tempo as pesquisas científicas foram atravessadas por discursos coloniais, silenciando as questões voltadas para essa temática e contribuindo para as desigualdades.

O cenário político atual do nosso país corrobora sérios problemas de concepção em relação às questões de diversidade e execução de políticas de formação docente que tratem a temática como um pilar pedagógico. Num período como o que vivemos atualmente, em que as estruturas governamentais deixam de investir em ações afirmativas para a sociedade brasileira ${ }^{2}$ e sua educação, produzir conhecimentos sobre as relações étnico-raciais é não somente comprometer-se com uma causa histórica e sociológica, mas é também defender princípios de alteridade, fazendo valer o direito de todos ao conhecimento.

Munanga (2005) reflete que a falta de conhecimentos sobre a história da África, a cultura do negro no Brasil, a própria história do negro, e dos povos indígenas, de um modo geral, na formação docente constituem-se como um grande problema da legislação que implementa a obrigatoriedade desse ensino. Segundo o autor, não se trata apenas da falta do conhecimento teórico, mas também do que o estudo dessa temática implica: o enfrentamento e a derrubada do mito da democracia racial que paira sobre o imaginário da grande maioria dos(as) educadores (as).

\footnotetext{
${ }^{2}$ O Governo Federal, que desde janeiro de 2019 está sob o comando de políticos de extrema direita, em uma de suas primeiras ações, extingue a Secretaria de Educação Continuada, Alfabetização, Diversidade e Inclusão (Secadi), movimentando-se contrariamente aos direitos conquistados através da luta popular e desconsiderando a educação como parte do processo de emancipação social.
} 
As relações étnico-raciais constituem uma das temáticas desenvolvidas e problematizadas nas políticas sociais e especificamente nas políticas educacionais. Seu desenvolvimento e a sua problematização deram-se, a priori, pelo debate internacional sobre a temática e pelas ações dos movimentos sociais que defendem a sua visibilização e inserção no ambiente escolar. Ao Estado, coube a sua efetivação através de leis e resoluções. A discussão sobre a temática e o desenvolvimento de estratégias políticas que a contemplam são resultados da influência do Programa de Combate ao Racismo Institucional, coordenado pela ONU; dos debates globais sobre o combate ao racismo e à discriminação racial, dos debates nacionais que instituíram legislações específicas para a temática, e dos debates locais, fomentados pelo movimento negro.

Apresentamos a seguir o caminho percorrido para o desenvolvimento de políticas educativas voltadas à temática étnico-racial e para criação do Grupo de Trabalho em Educação para as Relações Étnico-Raciais-GTERE, através da Portaria nº 489, de 21 de março de 2006 cujo objetivo era de fomentar junto aos docentes municipais de Recife a discussão sobre pedagogias e projetos educativos emancipatórios; e ainda o Conselho Municipal de Políticas de Promoção da Igualdade Racial (CMPPIR), criado em 2007, através da lei $\mathrm{n}^{\circ} 17.311$, que tinha como finalidades: propor ações afirmativas de promoção da igualdade racial, com vistas à ampliação da participação popular e do controle social; acompanhar, monitorar e fiscalizar tais ações; e fortalecer a luta contra o racismo e o preconceito baseado em raça ou etnia. É preciso evidenciar que a criação do $\mathrm{GTERE}^{3}$ é no contexto local fruto das reflexões e proposições da Plenária de Negros e Negras do Orçamento Participativo (2004) e da I Conferência Municipal de Promoção da Igualdade Racial realizada em 2005. São atribuições do GTERE ${ }^{4}$ :

- Formações continuadas com profissionais da Educação;

- Seminários;

- Análise de material didático e pareceres;

- Rodas de diálogos nas escolas da Rede;

\footnotetext{
${ }^{3}$ Além da representação do nome do grupo GTERE (Grupo de Trabalho em Educação das relações ÉtnicoRaciais), o radical ERÊ é uma palavra que vem do Yorubá e significa brincadeira, divertimento, jogo, vibração infantil. Na corrente de um orixá, o ERÊ aparece instantaneamente logo após o transe, ou seja, ele é o intermediário entre o iniciado e o orixá. Não confundir com criança, que em Yorubá é Omodé (Fonte: folder do GTERE-2011).

${ }^{4}$ Material apresentado pela professora Fátima Oliveira (técnica do GTERE) no III Seminário Internacional Educação e Cultura: Resistências e Identidades em Movimento na América Latina, promovido pela Fundaj (Fundação Joaquim Nabuco), em dezembro de 2018.
} 
Ações Intersetoriais - Sec. Juventude/Direitos Humanos/Gerência de Igualdade Racial (GERIR);

- Participações em audiências, conferências do Conselho Municipal de Promoção de Política de Igualdade Racial (CMPPIR); Monitoramento e avaliação das Políticas de Igualdade Racial; Estudos específicos no Centro de Formação e Estudos ampliados com as demais equipes técnicas.

\section{O Ciclo de Políticas na análise de políticas educacionais voltadas à temática étnico-racial e para criação do GTERE}

A fim de explicitar o uso da abordagem do Ciclo de Políticas na análise da temática das relações étnico-raciais, é importante deixar claro quais eventos são considerados nos diferentes contextos. Tais eventos compõem um conjunto articulado, mesmo que não de forma claramente intencional, que sustenta a política educacional em questão.

A cronologia de tais eventos não pode ser vista como uma construção linear e objetiva visando à execução de dada política, mas sim ser entendida a partir da própria contradição e desenvolvimento destas mesmas ações ao demandarem outros eventos de modo a ir caracterizando a política. É assim que um dado evento, ao mesmo tempo, responde ao contexto e é por esse influenciado.

Assim, destacamos aqui os eventos considerados em cada nível - global, nacional e local - relacionados pela ordem de sua realização.

No nível global, os eventos abaixo relacionados se destacam como contextos influentes:

- I Convenção Internacional sobre a Eliminação de todas as formas de Discriminação Racial - 1965.

- II Conferências Mundiais contra o Racismo, a Discriminação Racial e as Intolerâncias Correlatas, realizada na cidade de Genebra, na Suíça - Entre 1978 e 1983 (3 edições).

- III Assembleia Geral da ONU (Institui as décadas de Combate ao Racismo e à Discriminação Racial) (1983)

No nível nacional, os eventos abaixo relacionados se destacam como contextos influentes, da produção de textos e das práticas:

- Constituição de 1988 - Repúdio ao racismo e outras formas de discriminação. 
- Em 1988 a União Nacional dos Dirigentes Municipais (UNDIME), a Secretaria de Educação de Recife e comissões de diversos municípios, se unem a fim de elaborar um projeto a ser encaminhado ao Ministério da Cultura para obter recursos necessários para a implantação do projeto "As escolas municipais descobrindo-se negras".

- Criação do Grupo de Trabalho Interministerial de Valorização da População Negra, criado por decreto presidencial em 1995

- A primeira Marcha Zumbi contra o Racismo, pela Cidadania e pela Vida foi realizada no dia 20 de novembro de 1995. Cerca de 30 mil pessoas se reuniram em Brasília para denunciar a ausência de políticas públicas para a população negra.

- I Congresso Brasileiro de Pesquisadores/as Negros/as, realizado de 22 a 25 de novembro de 2000 em Recife (Pernambuco).

- Aprovação do Estatuto da Criança e Adolescente em 1990 que ratifica a importância do respeito e da valorização da identidade e da cultura afro-brasileira (BRASIL, 1990).

- Aprovação da Lei de Diretrizes e Bases da Educação Nacional-LDBEN - 9. 314/96 - Educação Antirracista

- O Conselho Nacional de Educação aprova em 1996 as Diretrizes Curriculares Nacionais para a Educação das Relações Étnicos Raciais (DCNERER).

- Fundação da Associação Brasileira de Pesquisadores Negros (ABPN). A ABPN é responsável pelo Congresso Brasileiro de Pesquisadores Negros (Copene) em 2000.

- Participação do Brasil na III Conferência Mundial sobre Racismo, Discriminação Racial e Intolerâncias Correlatas, realizada em Durban, na África do Sul (2001).

- Em 09 de janeiro de 2003, a aprovação da Lei no 10.639, outra demanda do Movimento Negro foi contemplada e que alterou a Lei $n^{\circ}$ 9394/96, determinando a inclusão dos artigos 26-A e 79-B na LDBEN, referente à obrigatoriedade do ensino de história e cultura africana e afro-brasileira nas escolas públicas e privadas dos ensinos Fundamental e Médio.

- Aprovação da Lei n ${ }^{\circ}$ 11.645/2008, que obriga os estabelecimentos de ensino a inserir a História e Cultura Afro-Brasileira e Indígena no currículo escolar, regulamentada pelo Parecer CNE/CP 03/04 e pela Resolução CNE/CP 01/04.

- Criação do Grupo de Trabalho Interministerial de Valorização da População Negra, criado por decreto presidencial em 1995 
- O Ministério da Educação cria em 2003 a Secretaria de Políticas de Promoção da Igualdade Racial (SEPPIR).

- Criação em 2004 da Secretaria de Educação a Distância, Alfabetização e Diversidade (Secad), um órgão componente da estrutura administrativa do Ministério da Educação (MEC). Posteriormente renomeada Secadi (Secretaria de Educação Continuada, Alfabetização, Diversidade e Inclusão).

- Criação da Comissão Técnica Nacional de Diversidade (CADARA) para Assuntos Relacionados à Educação dos Afro-Brasileiros. Instituída pela Portaria no 4.542, de 28 de dezembro de 2005.

No nível local, os eventos abaixo relacionados se destacam como contextos influentes, da produção de textos e das práticas:

- VIII Encontro de Negros do Norte e Nordeste, realizado entre os dias 29 e 30 de julho de 1988. Organizado pelo Movimento Negro Unificado e pela Escola Maria da Conceição. O evento tinha como tema "O Negro e a Educação".

- A Prefeitura do Recife abraça o Programa de Combate ao Racismo Institucional (PCRI), e as questões raciais são inseridas no contexto da administração municipal em 2004.

- A criação do GTERE foi fruto das reflexões e proposições da Plenária de Negros e Negras do Orçamento Participativo (2004) e da I Conferência Municipal de Promoção da Igualdade Racial realizada em 2005.

- Criação do Conselho Municipal de Políticas de Promoção da Igualdade Racial (CMPPIR), criado em 2007, através da lei no 17.311 com a finalidade de propor ações afirmativas de promoção da igualdade racial, com vistas à ampliação da participação popular e do controle social; acompanhar, monitorar e fiscalizar tais ações; e fortalecer a luta contra o racismo e o preconceito baseado em raça ou etnia.

- Criação e realização do Projeto As Escolas Municipais descobrindo-se Negras onde foram realizadas caminhadas e concursos literários.

Em Recife, no ano de 2016, a gestão municipal revoga a Portaria n $^{\circ} 489$, de março de 2006 e publica a Portaria $\mathrm{n}^{\mathrm{o}} 29$ de 29 de janeiro de 2016, atualizando a nova composição do GTERE, e regulamenta o funcionamento, determinando que, a partir de então, a participação do grupo limita-se à formação continuada da Escola de Formação de Educadores do Recife Professor Paulo Freire. Diante disso, o Grupo de Trabalho passa a compor a equipe de formação, tendo assim sua autonomia propositiva enfraquecida desde então. 
Diante da mudança apontada acima, ocorrida em 2016, a citação que segue nos permite compreender a importância do tempo e espaços nos diversos contextos na dimensão histórica e política na arena educacional que compreender os níveis global, nacional e local:

\begin{abstract}
Segundo Ball, podemos refletir a respeito das políticas em termos de espaços e em termos de tempo, de trajetórias políticas, movimentos de políticas através do tempo e de uma variedade de espaços. Uma política tem uma trajetória semelhante à de um foguete: decola, atravessa o espaço e depois aterrissa. Algumas vezes, acidenta-se; em outras, atinge uma realização espetacular, mas move-se através do tempo e, algumas vezes, simplesmente desaparece. As políticas desaparecem no decorrer do tempo ou, algumas vezes, leva muito tempo para elas se tornarem integradas. Algumas vezes, elas são apressadas ou atrasadas. É necessário pensar sobre a velocidade das políticas, é necessário ter a dimensão do tempo, bem como do espaço. (MAINARDES; MARCONDES, 2009, p. 307).
\end{abstract}

\title{
Contextos Políticos e Sociais dos Períodos de Desenvolvimento das Políticas local
}

Esta categoria de análise se refere aos cenários políticos e sociais na cidade do Recife, nos períodos da gestão estudada. Os dados apontam que a fase em que o petista João Paulo de Lima e Silva esteve à frente do executivo municipal (2001 a 2008) foi fortemente marcada pela atenção dada às mobilizações populares e às reivindicações dos movimentos sociais. Com caráter progressista, a gestão que trazia como lema "A grande Obra é cuidar das pessoas!" buscou atuar de modo a valorizar mais a inclusão e a diversidade. Para isso, a gestão encontrou respaldo nos integrantes da rede que participavam, em sua maioria, dos movimentos sociais, e contribuíram para essa articulação.

É neste movimento como já dissemos na seção anterior que, em 2004, a Prefeitura do Recife faz adesão ao Programa de Combate ao Racismo Institucional (PCRI), inserindo a temática das questões raciais no contexto da administração municipal. Contudo, o Decreto $\mathrm{n}^{\circ}$ 24.301, que institui tal programa, só é publicado quatro anos depois, em 29 de dezembro de 2008. O principal objetivo do PCRI é desenvolver na administração pública a capacidade de identificação e realização de ações de prevenção do racismo institucional, estimulando a participação das organizações da sociedade civil no debate sobre políticas públicas racialmente equitativas (Decreto n 24.301 da cidade do Recife, de 29 de dezembro de 2008).

As ações desenvolvidas pelo programa acima citado no Recife configuram-se fundamentais para o aprofundamento do debate e para a construção de uma agenda municipal de políticas intersetoriais voltadas para o enfrentamento do racismo. Neste sentido, as secretarias formaram equipes específicas, que elaboravam planos de ação setoriais e planejavam coletivamente. Ao longo de 2004, foram realizadas diversas reuniões entre essas equipes e 
representantes dos movimentos sociais e do Ministério Público, formando a partir daí o Grupo de Trabalho (GT) Racismo. A partir do aporte e das discussões realizadas pelo GT Racismo, e dos planos de ação das secretarias que o compõem, no ano de 2005, as ações do PCRI começaram a ser estendidas ao grande público, projetando, ainda que de forma modesta, a agenda de políticas de promoção da Igualdade Racial.

No âmbito educacional, a Lei $\mathrm{n}^{\circ} 10.639 / 2003$ ainda era desconhecida pela maioria dos educadores, o que dificultava a efetivação da mesma. Como resposta a essa realidade e sob influência das ações do PCRI, é criado o GTERE (Grupo de Trabalho em Educação das Relações Étnico-Raciais), através da Portaria nº 489. A referida Portaria, divulgada em Diário Oficial do dia 21 de março de 2006 e emitida pela Secretaria de Educação, informa sobre a organização do Grupo, suas atribuições, e sobre a composição do mesmo, que deve contar com 03 (três) membros da coordenação do PCRI em educação e 12 (doze) representantes das diversas gerências e Diretorias da Secretaria de Educação, Esporte e Lazer. O documento determina sobre a coordenação executiva do grupo, que deve ser assumida por um representante da equipe base do PCRI do Setorial Educação; orienta sobre a elaboração de um regulamento interno que especifique o funcionamento do grupo, a organização e a forma de trabalho do mesmo; e ainda estabelece que a infraestrutura e o apoio administrativo para o funcionamento do GTERE são de responsabilidade da Secretaria de Educação, Esporte e Lazer.

Além dos Grupos de Trabalhos (GT’s) foram criados alguns conselhos, tais como o Conselho Municipal de Políticas de Promoção da Igualdade Racial (CMPPIR). O referido Conselho foi criado em 2007, através da lei $\mathrm{n}^{\circ}$ 17.311, que dispõe sobre a criação do órgão colegiado, e suas finalidades: fortalecer a luta contra o racismo e o preconceito baseado em raça ou etnia, através de acompanhamento, monitoramento e fiscalização; além de propor ações afirmativas de promoção da igualdade racial, com vistas à ampliação da participação popular e do controle social.

A importância dos educadores na construção de reflexões étnico-raciais em sala de aula é um consenso, todavia, muitos(as) docentes não são formados(as) para desempenhar esse papel transformador, pois, em sua formação, não recebem orientações que auxiliem a sua prática. Gomes (1996) aponta em suas pesquisas que nem todos os docentes têm o preparo e a compreensão para atuar nesses aspectos, chamando a atenção sobre o quanto os educadores encontram-se desatentos ao fato de que a educação e a raça são relações imersas na alteridade, e o quanto os mesmos, em suas práticas, ainda contribuem para a transmissão de valores raciais que retroalimentam teorias que legitimam o racismo presente na prática escolar e social. Para a 
autora, "A prática dos professores está distante de uma análise histórica, sociológica, política e antropológica sobre a diversidade étnico-cultural" (GOMES, 1996, p. 74).

Essas dificuldades na abordagem da questão racial por parte dos docentes revelam as lacunas em suas formações profissionais, o despreparo para lidar com sujeitos socioculturais diversos. Silva (2018) também pontua sobre a importância de desenvolver processos formativos permanentes para os docentes, no sentido de garantir que situações de conflito entre alunos e professores sejam abordadas adequadamente, para combate ao racismo e às discriminações. Esse é um problema profissional e também político, que só poderá ser encarado com formação específica.

Os (as) professores (as) não devem silenciar diante dos preconceitos e discriminações raciais. Antes, devem cumprir o seu papel de educadores (as), construindo práticas pedagógicas e estratégias de promoção da igualdade racial no cotidiano da sala de aula. Para tal, é importante saber mais sobre a história e a cultura africana e afro-brasileira, superar opiniões preconceituosas sobre negros e índios, denunciar o racismo e a discriminação racial e implementar ações afirmativas para o povo negro, ou seja, é preciso superar e romper com o mito da democracia racial. (GOMES, 2005, p. 60).

Sabe-se que o desempenho do(a) educador(a) em sala de aula tem uma estreita relação com sua formação profissional e sua formação continuada. As leis $n^{\circ} 10.639 / 2003$ e $n^{\circ}$ 11.645/2008 impõem um desafio à formação continuada de educadores (as), em função da invisibilidade da temática nos currículos dos cursos de formação docente.

Na perspectiva de compreender como no contexto da prática se deu a efetivação do GTERE, foram entrevistados profissionais do grupo que faziam parte do GTERE na época de sua formação, assim como pessoas que estiveram à frente da Secretaria Municipal de Educação de Recife e da Diretoria de Ensino no período da criação do GTERE. As profissionais entrevistadas foram aqui identificadas como Respondentes e na sequência o número que correspondente à ordem das entrevistas.

Ainda em 2008, a rede de ensino estava tão empenhada em fazer valer a lei 10.639/03 que, através de propositivas do GTERE, além de fomentar debates sobre as questões étnicoraciais, contemplou a temática em seus diários de classe, que passaram a conter um item específico sobre isso, inserindo, inclusive, esse ponto nas vivências formativas com os educadores, como podemos observar na fala de uma das pessoas entrevistadas:

“(...) Nós construímos os diários de classe. Então, os diários de classe tinham, na sua capa, como se fosse uma diretriz do que é que a partir daquele momento, se defendia, e se faria, com relação à lei 10.639." (Respondente 4). 
Respondentes relatam também o contexto mobilizador que unia governo municipal, sociedade civil e organizações diversas para o desenvolvimento de debates e ações afirmativas nesse sentido, como pode ser observado nas falas a seguir:

“(...) $\mathrm{Na}$ época muitos dos militantes do movimento negro acessaram cargos gestores. (...) E, se tinha uma ligação com outros integrantes do movimento negro no país.” (Respondente 4).

“(...)Existia também essa articulação para além da secretaria (de educação). Isso era uma diretriz que vinha da gestão municipal, como um campo de prioridade (...) Existia um reconhecimento dos movimentos sociais, das organizações sociais." (Respondente 3).

“(...)Foi um momento muito bonito, porque a gente envolveu não só a secretaria de educação, mas todas as outras secretarias que trabalhavam na mesma linha, pra interagir com a educação. O movimento negro, incluímos todo mundo. Também tinha coisa fundamental: que era o apoio do MEC, através da SECAD (que depois virou SECADI), que apoiava a formação. (...)a SECAD dava todo o apoio pra gente. Mandava pessoal, mandava gente. E a gente tinha o apoio, inclusive, da linha político-pedagógica, pra não ter risco de errar. A gente também tinha uma vantagem de já ter uma prefeitura com um projeto sendo implementado institucionalmente." (Respondente 2).

“(...)Nessa gestão do PT, você tinha muita ação, você tinha muitos projetos, potencializavam os grupos, os trabalhos educativos de vários aspectos." (Respondente 6).

"Esse período, eu acho que foi bem produtivo, bem intensificado. A gente via mais coisas acontecendo(...)Diversos membros do GTERE já eram militantes de movimentos sociais." (Respondente 1).

Ao analisarmos as falas das profissionais que atuaram na Secretaria de Educação de Recife e no GTERE entre os anos de 2005 e 2008, percebemos que as mesmas destacam as várias iniciativas políticas e organizacionais que favoreceram a execução de diversas ações para execução da Lei 10.639/2003. Os relatos destacam o perfil democrático e participativo que caracterizou o período, a existência de diálogo com os movimentos sociais e com as universidades e o desenvolvimento de ações que fortaleceram a educação das relações étnicoraciais e incentivaram o debate sobre a temática, dentre elas a formação continuada de professores. Os debates globais sobre o combate ao racismo e à discriminação racial, o PCRI, coordenado pela ONU, os debates nacionais, que instituíram legislações específicas para a temática, e os debates locais, fomentados pelo movimento negro, do qual alguns dos seus representantes passaram a ocupar espaços no governo municipal, constituíram o contexto da influência social e política e da produção de textos que efetivaram no Recife a política educacional das relações Étnico-raciais na rede municipal na gestão João Paulo. Este movimento instituiu o GTERE que foi o espaço na secretaria de educação que originou projetos e normativas que garantiu a efetivação das políticas nas práticas pedagógicas dos educadores 
(Contexto da Prática). A abordagem do Ciclo de Políticas (BALL, 1994) nos possibilitaram entender este movimento no contex to das políticas afirmativas no Brasil e mais especificamente na rede municipal do Recife.

A pesquisa nos possibilitou compreender o objeto em análise a partir da escuta dos grupos de interesse representados assim como dos grupos excluídos nesses processos, onde identificamos vozes predominantes, suas intencionalidades, suas inconsistências e contradições. Dessa forma, compreendemos que a política não é finalizada no texto político, uma vez que há embates pelo controle de seu significado, pois a política "[...] estabelece limites sobre o que é permitido pensar e tem o efeito de distribuir vozes, uma vez que somente algumas vozes serão ouvidas como legítimas e investidas de autoridade” (MAINARDES, 2006, p. 8).

A maioria dos entrevistados, em suas falas, destaca a necessidade de uma educação voltada para as relações de etnias e raças, como uma reparação histórica para com os diversos povos, visto que o eurocentrismo predomina no campo curricular educacional. Também chamam a atenção para a atual falta de interesse político na temática étnica e racial, e para as desigualdades vivenciadas atualmente nos diversos espaços de poder da Secretaria de Educação de Recife, assim como em tantos outros espaços sociais.

\section{Conclusão}

O presente artigo busca contribuir com a área de política educacional discutindo e analisando a experiência de uma orientação em nível de mestrado que utilizou a abordagem do Ciclo de Políticas para o entendimento de uma dada política educacional, no caso, a constituição do setor de Política das Relações Étnico-raciais em uma rede de ensino municipal.

O uso desta abordagem, muito mais que servir de aporte teórico para fundamentação da análise, se mostra como a própria organização teórico e metodológica da pesquisa, visando sua integração como característica intrínseca da análise. Segundo Mainardes (2018, p. 10),

Nos estudos predominantemente analíticos, os dados ou as ideias são trabalhados, categorizados, comparados. Uma das características importantes dos estudos analíticos é mais integração entre teoria e dados. As teorias não são meramente aplicadas, pois o esforço de análise resulta na geração de conceitos, de categorias, de tipologias, de generalizações empíricas.

A temática das relações étnico-raciais - foco da pesquisa aqui analisada - tem sido explorada por diferentes pesquisadores que se utilizam de perspectivas teóricas distintas com o objetivo de caracterizar tal fenômeno social e dele extrair significados e repercussões para a prática social. O estudo em questão, ao utilizar o Ciclo de Políticas proposto por Ball e 
seguidores, visa superar a mera utilização de referenciais teóricos e metodológicos, para poder integrar teoria e dados em um quadro analítico que consiga desvelar as relações e influências e mesmo as contradições deste processo.

Os eventos identificados nos diferentes tempos e espaço a partir da análise dos contextos revelaram ao mesmo tempo a inexistência quase total, até então, de elementos para a constituição da política das relações étnico-raciais no âmbito desta secretaria de educação, bem como a insurgência de outros atores na cena política, nos diversos níveis, que tensionaram as disputas em torno deste campo específico, particularmente no que diz respeito à necessidade de mudanças tanto na organização como nos relacionamentos.

No tocante à inexistência de elementos para a constituição da política de relações étnicoraciais, destaca-se a insuficiência de recursos humanos com formação e vivências específicas para a execução de tais projetos, particularmente de gestores da administração municipal. Tais atores sociais se apresentam na cena política marcados principalmente por uma prática social de gestão de políticas públicas que não consideravam as relações de discriminação e desigualdade racial, fazendo com que tais temáticas fossem relegadas a um plano secundário na elaboração das políticas públicas.

Por outro lado, a insurgência de novos atores na cena política abre perspectivas até então não consideradas na política pública. Tais atores surgem e dinamizam o contexto de influência a partir de outros referenciais que não eram considerados na elaboração dessa política. Esses atores, além de carregarem compreensões próprias sobre o fenômeno da discriminação racial, por exemplo, incentivam e mesmo produzem práticas distintas, que mesmo já sendo conhecidas, trazem um novo significado para a cena política. É assim que podemos perceber as diversas manifestações públicas sobre a necessidade de instauração de uma política específica para as relações étnico-raciais no âmbito da secretaria de educação, e mesmo na prefeitura em geral. E também a realização de eventos científicos e culturais que divulguem amplamente a necessidade de efetivação de tal política.

Por fim, é oportuno reafirmar que o uso da abordagem do Ciclo de Políticas permitiu ampliar a compreensão do fenômeno em análise - a execução da política de relações étnicoraciais - não a limitando a uma simples verificação de aplicação de determinada teoria, mas, ao contrário, desvelando os caminhos, por vezes contraditórios, de sua construção.

Outrossim, é válido destacar que o processo de orientação acadêmica, que está na base da construção deste estudo, apoiado na dinâmica de análise proposta pela abordagem do Ciclo de Políticas, se valeu desta mesma perspectiva ao romper cânones clássicos da epistemologia no que diz respeito tanto ao modo de fazer como aos sujeitos responsáveis pela produção do 
conhecimento em questão, permitindo uma configuração de trabalho acadêmico que valoriza a produção feita pelo orientando.

\section{REFERENCIAS}

ANDRÉ, Marli. O que é um estudo de caso qualitativo em educação? Revista da FAEEBA Educação e Contemporaneidade, Salvador, v. 22, n. 40, p. 95-103, jul./dez, 2013.

AZEVEDO, Janete M. Lins de. A Educação como Política Pública. 2. ed. Campinas, SP: Autores Associados, 1997. 75 p. (Coleção Polêmicas do Nosso Tempo, v. 56)

BALL, Stephen J. Education reform: a critical and post structural approach. Buckingham: Open University Press, 1994.

BALL, Stephen J. Educação Global S. A.: novas redes de políticas e o imaginário neoliberal. Tradução de Janete Bridon. Ponta Grossa: UEPG, 2014.

BALL, Stephen J.; MAINARDES, Jefferson (Orgs.). Políticas Educacionais: questões e dilemas. São Paulo: Cortez, 2011.

BALL, Stephen J.; BOWE, Richard. Subject departments and the "implementation" of National Curriculum policy: an overview of the issues. Journal of Curriculum Studies, London, v. 24, n. 2, p. 97-115, 1992.

BOWE, Richard; BALL, Stephen J.; GOLD, Anne. Reforming education \& changing schools: case studies in Policy Sociology. London: Routledge, 1992.

BRASIL. Constituição. Constituição da República Federativa do Brasil. Brasília: Senado Federal: Centro Gráfico, 1988.

BRASIL. Decreto no 6.755, de 29 de janeiro de 2009. Institui a Política Nacional de Formação de Profissionais do Magistério da Educação Básica, disciplina a atuação da Coordenação de Aperfeiçoamento de Pessoal de Nível Superior - Capes no fomento a programas de formação inicial e continuada, e dá outras providências. Disponível em: http://www.planalto.gov.br/ccivil. Acesso em: 10 mar. 2020.

BRASIL. Educação anti-racista: caminhos abertos pela Lei Federal no 10.639/03. Brasília: MEC/SECAD, 2005. Disponível em: https://unesdoc.unesco.org/ark:/48223/pf0000143283. Acesso em: 12 jul. 2018.

BRASIL. Estatuto de Igualdade Racial. Lei n ${ }^{\circ}$ 12.288, de 20 de julho de 2010. Brasília, 2010. 
BRASIL. Ministério da Educação e Cultura. Lei no 10.678, de 23 de maio de 2003. Cria a Secretaria Especial de Políticas de Promoção da Igualdade Racial (SEPPIR), da Presidência da República, e dá outras providências. Brasília, DF. Disponível em:

<http://www.planalto.gov.br/ccivil_03/LEIS/2003?L10.678.htm>. Acesso em: 15 set. 2017.

BRASIL. Ministério da Educação. Gabinete do Ministro. Portaria no 4.542, de 28 de dezembro de 2005. Institui a Comissão Técnica Nacional de Diversidade para Assuntos Relacionados à Educação dos Afro-brasileiros - CADARA, com o objetivo de elaborar, acompanhar, analisar e avaliar políticas públicas educacionais, voltadas para o fiel cumprimento do disposto na Lei 10.639/2003, visando a valorização e o respeito à diversidade étnico-racial, bem como a promoção de igualdade étnico-racial no âmbito do Ministério da Educação - MEC. Diário Oficial da União, Brasília, DF, 29 dez. 2005. p. 18.

BRASIL. Parecer 03/2004 do Conselho Pleno do Conselho Nacional de Educação. Brasília: MEC, 2004.

. MEC. SECAD. Diretrizes Curriculares Nacionais para a Educação das Rel
Étnico-Raciais e para o Ensino de História e Cultura Afro-Brasileira e Africana. Brasília: MEC, 2004.

Secretaria Especial de Políticas de Promoção da Igualdade Racial (SEPPIR),

Relatório de Gestão 2003-2006, SEPPIR, 2006. Disponível em:

$<$ http://www.presidencia.gov.br/estrutura_presidencia/seppir/publicacoes/relatorio_gestao_20 03_2006.pdf>. Acesso em: 10 set. 2017.

COORDENAÇÃO DE APERFEIÇOAMENTO DE PESSOAL DE NÍVEL SUPERIOR CAPES. Plataforma Sucupira. Cursos Avaliados e Reconhecidos, 2016.

CORREIA, Danielle Silva da Rocha. A política de Formação docente para a educação das relações Étnico-Raciais na Rede Municipal de Educação do Recife e o Grupo de Trabalho em Educação para as Relações Étnico-Raciais - GTERE (2006-2018). 2020. Dissertação (Mestrado em Educação, Culturas e Identidades) - Programa Associado Universidade Federal Rural de Pernambuco, Fundação Joaquim Nabuco, Recife, 2020.

FREIRE, Paulo. Pedagogia da Autonomia. São Paulo: Paz e Terra, 1996.

GOMES, Nilma Lino. Educação, Raça e Gênero. Cadernos Pagu (6-7), pp. 67-82, 1996.

GOMES, Nilma Lino. Alguns termos e conceitos presentes no debate sobre relações raciais no Brasil: uma breve discussão. In: BRASIL. Educação Anti-racista: caminhos abertos pela Lei federal $n^{\circ}$ 10.639/03. Brasília, MEC, Secretaria de educação continuada e alfabetização e diversidade, 2005. p. $39-62$.

LOPES, Alice Casimiro. Políticas curriculares: continuidade ou mudança de rumos? Revista Brasileira de Educação, Rio de Janeiro, n. 26, p. 109-118, 2004. 
MAINARDES, Jefferson. Abordagem do Ciclo de Políticas: Uma contribuição para a análise de Políticas Educacionais. Educ. Soc., Campinas, v. 27, n. 94, p. 47-69, jn/abr. 2006.

MAINARDES, Jefferson. A Abordagem do Ciclo de Políticas: Explorando alguns desafios da sua utilização no campo da Política Educacional. Jornal de Políticas Educacionais, Curitiba, v. 12, n. 16, p. 01-19, Agosto. 2018.

MAINARDES, Jefferson; MARCONDES, Maria Inês. Entrevista com Stephen J. Ball: um diálogo sobre justiça social, Pesquisa e Política Educacional. Educação e Sociedade.

Campinas, v. 30, n. 106, p. 303-308, jan.-abr. 2009.

MOVIMENTO NEGRO UNIFICADO. Relatório do VIII Encontro de Negros do Norte e Nordeste. Tema: O Negro e a Educação. Recife: Companhia Editora de Pernambuco, 1988.

MUNANGA, Kabengele. Superando o racismo na escola. Brasília: Ministério da Educação, Secad, 2005.

RECIFE (Prefeitura). Decreto $\mathbf{n}^{\mathbf{0}}$ 24.301, de 29 de dezembro de 2008. Dispõe sobre a instituição do Programa de Combate ao Racismo Institucional - PCRI do Recife. Disponível em: https://leismunicipais.com.br/a/pe/r/recife/decreto/2008/2431/24301/decreto-n-243012008-institui-o-programa-de-combate-ao-racismo-institucional-pcri-do-recife. Acesso em: 06 fev. 2019.

RECIFE (Prefeitura). Lei $\mathbf{n}^{\mathbf{0}}$ 17. 311, de 28 de março de 2007. Dispõe sobre a Criação do Conselho Municipal de Políticas de Promoção da Igualdade Racial. Disponível em: https://leismunicipais.com.br/a/pe/r/recife/lei-ordinaria/2007/1732/17311/lei-ordinaria-n17311-2007-cria-o-conselho-municipal-de-politicas-de-promocao-da-igualdade-racial. Acesso em: 05 fev. 2019.

RECIFE (Prefeitura). Portaria de $n^{\circ} 29$, de 29 de janeiro de 2016. Dispõe sobre a regulamentação do GTERE e revoga a Portaria nº 489, de 21 de março de 2006. Disponível em: http://www.recife.pe.gov.br/diariooficialacervo/exibemateria.php?cedicacodi $=12 \&$ aedicaano $=2016 \&$ ccadercodi $=2 \&$ csecaocodi $=71 \& c$ matercodi $=1 \& Q P=$ cultura + afro $\& \mathrm{TP}=$. Acesso em: $05 \mathrm{dez} .2019$.

RECIFE (Prefeitura). Portaria no 489, de 21 de março de 2006. Dispõe sobre a criação do Grupo de Trabalho que trata de Educação e Relações Étnico-Raciais- GTERE. Disponível em: http://www.recife.pe.gov.br/diariooficialacervo/exibemateria.php?cedicacodi $=33 \&$ aedicaano $=2006 \&$ ccadercodi $=2 \&$ csecaocodi $=32 \& c$ matercodi $=1 \& Q P=$ cultura + afro $\& T P=$. Acesso em: 20 jan. 2019.

SILVA, Petronila Beatriz Gonçalves e. 10 anos da lei no 10.639/03- Um olhar críticoreflexivo. Seminário Virtual Nacional. História e cultura Africana e Afro-brasileira na escola. Conquistas, desafios e perspectivas: 10 anos da lei $\mathrm{n}^{\circ}$ 10. 369/03. Disponível em: http://menotti.fundaj.gov.br/moodle/course/view.php?id=3. Acesso em: 21 ago. 2018.

SILVA, Petronila Beatriz Gonçalves e. Educação das Relações Étnico-Raciais nas instituições escolares. Educar em Revista, Curitiba, Brasil, v. 34, n. 69, p. 123-150, maio/jun, 2018. 
SOBRE AS AUTORAS:

\section{Ana de Fátima P. de Sousa Abranches}

Doutora em Educação (UFPE), Analista em C\&T Pleno da Fundação Joaquim NabucoFundaj/MEC, Recife, docente do Mestrado em Educação, Culturas e Identidades (UFRPE/Fundaj) e docente do Mestrado Profissional de Sociologia em Rede Nacional (Fundaj) - Laboratório de estudos sobre Educação no Nordeste - ana.abranches@ fundaj.gov.br

iD https://orcid.org/0000-0003-2704-4401

\section{Danielle Silva da Rocha Correia}

Mestre em Educação, Culturas e Identidades. (UFRPE/Fundaj). Docente da Educação Básica na Secretaria de Educação, Esportes e Juventude, Olinda, Daniellesilva.ufpe@ bol.com.br iD https://orcid.org/0000-0001-7918-1307 